Journal of Animal and Veterinary Advances 9 (8): 1259-1264, 2010

ISSN: $1680-5593$

(C) Medwell Journals, 2010

\title{
Effects of Cooking Techniques and Levels on the Formation of Heterocyclic Aromatic Amines in Chicken and Fish
}

\author{
F. Oz, G. Kaban and M. Kaya \\ Department of Food Engineering, Faculty of Agriculture, Atatürk University, 25240 Erzurum, Turkey
}

\begin{abstract}
The effects of different cooking methods (microwave, oven, hot plate, pan-frying and barbecuing) and levels (rare, medium, well done and very well done) on the formation of heterocyclic aromatic amines (HCAs) in chicken chops and fish fillets were investigated. The cooked samples were analyzed for nine HCAs, including 2-amino-3-methylimidazo [4,5-f]quinoline (IQ), 2-amino-3-methylimidazo [4, 5-f]quinoxaline (IQx), 2-amino-3, 4-dimethylimidazo [4, 5-f]quinoline (MeIQ), 2-amino-3, 8-dimethylimidazo [4, 5-f]quinoxaline (MeIQx), 2-amino-3, 4, 8-trimethylimidazo [4, 5-f]quinoxaline (4, 8-DiMeIQx), 2-amino-3, 7, 8-trimethylimidazo [4, 5f] quinoxaline (7, 8-DiMeIQx), 2-amino-1-methyl-6-phenylimidazo [4, 5-b] pyridine ( $\mathrm{PhIP}$ ), 2-amino-9H-pyrido [2, 3-b]indole $(\mathrm{A} \alpha \mathrm{C})$ and 2-amino-3-methyl-9H-pyrido [2, 3-b] indole (MeA $\alpha \mathrm{C})$. For chicken samples, while HCAs were only detected in barbecued chicken, it was determined that total HCA amount changed between 3.36 and $8.13 \mathrm{ng} \mathrm{g}^{-1}$. The highest total amounts found in very-well done barbecued chicken chops. It was determined that no HCAs detected in fish fillets cooked with microwave and hot plate. The highest total amounts found in fish for oven, pan-frying and barbecuing were $2.09,5.89$ and $3.52 \mathrm{ng} \mathrm{g}^{-1}$, respectively. $\mathrm{A} \alpha \mathrm{C}$ and $\mathrm{MeA} \alpha \mathrm{C}$ were not detected in any samples analyzed.
\end{abstract}

Key words: Heterocyclic aromatic amines, cooking techniques, cooking level, chicken, rainbow trout (Oncorhynchus mykiss), PRS

\section{INTRODUCTION}

Heterocyclic Aromatic amines (HCAs) are compounds that are formed naturally during cooking of proteinaceous foods such as meat and fish. Today, $>25$ various HCAs have been isolated and identified (Sanz Alaejos et al., 2008). Epidemiologic studies have shown that most HCAs are highly mutagenic (Felton et al., 1984) and almost all of them are also carcinogenic (Sugimura, 1995). The concentrations of HCAs depend on meat type, cooking procedures, $\mathrm{pH}$, water activity, carbohydrates, free amino acids, creatine, heat and mass transfer, lipid, lipid oxidation, antioxidants (Felton et al., 1997; Jägerstad et al., 1998; Pais et al., 1999; Oz and Kaya, 2006; Oz et al., 2007). It has been stated that human exposure to HCAs is influenced not only by the type of food and cooking method but also by portion size and intake frequency (Skog, 2004).

The aim of this study was to investigate the effects of different cooking methods (microwave, oven, hot plate, pan-frying and barbecuing) and cooking levels of doneness (rare, medium, well and very well) on the formation of HCAs in chicken chops and fillets of rainbow trout (Oncorhynchus mykiss).

\section{MATERIALS AND METHODS}

Chemicals and solvents were of High Performance Liquid Chromatography (HPLC) or analytical grade. Water was from a Milli-Q water purification system (Millipore, Bedford, Massachusetts, USA). All solutions were passed through a $0.45 \mu \mathrm{m}$ filter (Milex, Massachusetts, USA). HCA standards were purchased from Toronto Research Chemicals (Downsview, Ontario, Canada). 4,7,8TriMeIQx (2-amino-3,4,7,8-tetramethylimidazo [4, 5-f] quinoxaline) was used as the internal standard. The stock standard solutions were prepared according to $\mathrm{Oz}$ et al. (2007). Chicken chops were obtained from a local market. The fish, rainbow trout (Oncorhynchus mykiss), were obtained from Research and Extension Center of Fisheries Department in Agriculture Faculty at Ataturk University, Erzurum, Turkey. The fillets were prepared in laboratory.

Microwave, oven, hot plate, pan-fry and barbecue cooking methods were used in this study. Pre-cooking experiments were done to determine the cooking level of the samples. Cooking level (rare, medium, well and very well) of each sample was determined based on the results of these experiments. The cooking time of the samples cooked with different methods was given according to

Corresponding Author: F. Oz, Department of Food Engineering, Faculty of Agriculture, Atatürk University 25240, Erzurum, Turkey 
Table 1: Cooking time for the chicken chops and fish fillets (min)

\begin{tabular}{llccrc}
\hline \multirow{4}{*}{ Meat } & Cooking & Cooking level & & \\
\hline \multirow{2}{*}{ Chicken } & methods & Rare & Medium & Well & Very well \\
& Microwave & 3.0 & 6 & 9.0 & 12 \\
& Oven & 5.0 & 10 & 15.0 & 20 \\
& Hot plate & 5.0 & 10 & 15.0 & 20 \\
& Pan-frying & 5.0 & 10 & 15.0 & 20 \\
& Barbecuing & 3.0 & 6 & 9.0 & 12 \\
& Mish & 1.0 & 2 & 3.0 & 4 \\
& Oven & 3.0 & 6 & 9.0 & 12 \\
& Hot plate & 2.0 & 4 & 6.0 & 8 \\
& Pan-frying & 2.0 & 4 & 6.0 & 8 \\
& Barbecuing & 1.5 & 3 & 4.5 & 6 \\
\hline
\end{tabular}

their cooking levels in Table 1. For the microwave experiment, it was used a kitchen type microwave (Arcelik, Turkey). For microwaving of the samples, cooking was done by automatically selected degrees in microwave. For the oven experiment, it was also used a kitchen type oven (Arcelik, Turkey). For grilling, hot plate was used. The pan-frying process was carried out with a Teflon-coated pan. Before cooking with oven, hot plate and pan-frying, cooking surfaces was preheated to $200^{\circ} \mathrm{C}$ and then, samples were cooked. Temperatures were measured by using a digital thermocouple (part no. 0560 9260, Testo 926, Lenzkirch, Germany) with surface probe (0603 1992, Testo 926, Lenzkirch, Germany). For the charcoal barbecued, a bed of charcoal was prepared and ignited. When all flames had subsided, the bed was leveled by raking. No salt, spice, food additive and frying fat or oil were used in cooking procedures. All samples were turned over one a minute during the cooking time. After the cooking, samples were cooled at room temperature and homogenized using a kitchen blender to produce a uniform sample for analyses and frozen at $-18^{\circ} \mathrm{C}$ until analyzed for HCAs. They were thawed in a refrigerator at $4^{\circ} \mathrm{C}$ for $12-24 \mathrm{~h}$ prior to use. The raw chicken and trout samples were analyzed for moisture, total lipids and $\mathrm{pH}$ according to Gökalp et al. (1999). HCAs however, were only tested in cooked samples.

HCA extraction: HCA content was determined by the method described by the method described by Gross and Gruter (1992) with some modifications. One gram sample of cooked meat was dissolved in $12 \mathrm{~mL}$ of $1 \mathrm{M} \mathrm{NaOH}$. The suspension was homogenized by magnetic stirring for $1 \mathrm{~h}$ at $500 \mathrm{rpm}$. The alkaline solution was mixed with $13 \mathrm{~g}$ diatomaceous earth and then poured into empty LRC-PRS cartridges. The extractions were made with ethyl acetate and the eluate was passed through coupled diatomaceous earth extraction cartridges. Non-polar HCAs were eluted with $6 \mathrm{~mL}$ of $0.01 \mathrm{~N} \mathrm{HCl}, 15 \mathrm{~mL} \mathrm{MeOH:} 0.1 \mathrm{~N} \mathrm{HCl}$ (60:40) and $2 \mathrm{~mL}$ pure water. The eluat in beaker was kept in refrigerator. For the polar $\mathrm{HCAs}, \mathrm{C}_{18}$ cartridges (100 mg) were coupled with the system and the polar HCAs were eluted with $20 \mathrm{~mL}$ ammonium acetate, $2 \mathrm{~mL}$ water. The cartridges were dried under nitrogen and then $800 \mu \mathrm{L}$ of $\mathrm{MeOH}: \mathrm{NH}_{3}$ (9:1) was added and transferred to vials. To continue the non-polar $\mathrm{HCAs}, 500 \mu \mathrm{L} 32 \% \mathrm{NH}_{3}$ and $25 \mathrm{~mL}$ pure water were added to the beaker removed from refrigerator. $\mathrm{C}_{18}$ cartridges $(500 \mathrm{mg}$ ) were coupled with the system and were cleaned with $5 \mathrm{~mL} \mathrm{MeOH}$ and pure water. Then, the cartridges were dried under nitrogen and then $800 \mu \mathrm{L}$ of $\mathrm{MeOH}: \mathrm{NH}_{3}$ (9:1) was added and transferred to vials. After polar and non-polar HCAs extraction, $100 \mu \mathrm{L} \mathrm{MeOH}$ was added to vials and vials were stored at $-20^{\circ} \mathrm{C}$ until running.

HPLC analysis: The samples were analyzed on an Agilent 1100 HPLC with UV-DAD detector (Agilent, Waldbronn, Germany). For the analysis of HCAs, a reversed-phase material (Semi Micro ODS-80 TS column, $5 \mu \mathrm{m}, 250 \times 2 \mathrm{~mm}$ i.d.) from Tosoh Bioscience $\mathrm{GmbH}$ (Stuttgart, Germany) was used with the following HPLC conditions: solvent $\mathrm{A}$ was methanol/acetonitrile/water/acetic acid (8/14/76/2, $\mathrm{v} / \mathrm{v} / \mathrm{v} / \mathrm{v}$ ) at $\mathrm{pH} 5.0$ (adjusted with $25 \%$ ammonium hydroxide) and solvent $\mathrm{B}$ was acetonitrile. A linear gradient $(0 \% \mathrm{~B}, 0-12 \mathrm{~min} ; 0-30 \% \mathrm{~B}, 12-20 \mathrm{~min} ; 30 \% \mathrm{~B}$, 20-25 min) was used. Flow rate of the mobile phases was $0.3 \mathrm{~mL} \mathrm{~min} \mathrm{~m}^{-1}$ and the injection volume was $3 \mu \mathrm{L}$. Each injection volume contained $0.5 \mu \mathrm{L}$ of internal standard. Extraction recoveries were determined by spiking the samples.

Statistical analysis: A completely randomized design has been employed (two replicates) and results have been analyzed using SPSS 11.5 (SPSS).

\section{RESULTS}

Moisture, fat and $\mathrm{pH}$ values of chicken chops were determined as $74.99 \pm 1.26,3.90 \pm 0.66$ and $6.40 \pm 0.13 \%$, respectively. The same parameters for rainbow trout were $75.93 \pm 1.12,2.58 \pm 1.29$ and $6.43 \pm 0.16 \%$, respectively. The average recoveries of the HCAs varied between 26 and $75 \%$ for the PRS method. LOD (limit of detection $=3$ ) and LOQ (limit of quantification $=10$ ) values for this study have been detected as 0.003 and $0.01 \mathrm{ng} \mathrm{g}^{-1}$ according to Signal/Noise, respectively.

The HCA content of chicken chops: Data from the quantitative HPLC analysis of the HCAs in chicken extracted according to the PRS method, expressed in ng $\mathrm{g}^{-1}$ cooked chicken meat, were presented in Fig. 1. While IQ could not be detected in all chicken samples, including barbecued ones, no HCAs were detected in any samples cooked with microwave, oven, hot-plate and pan- 


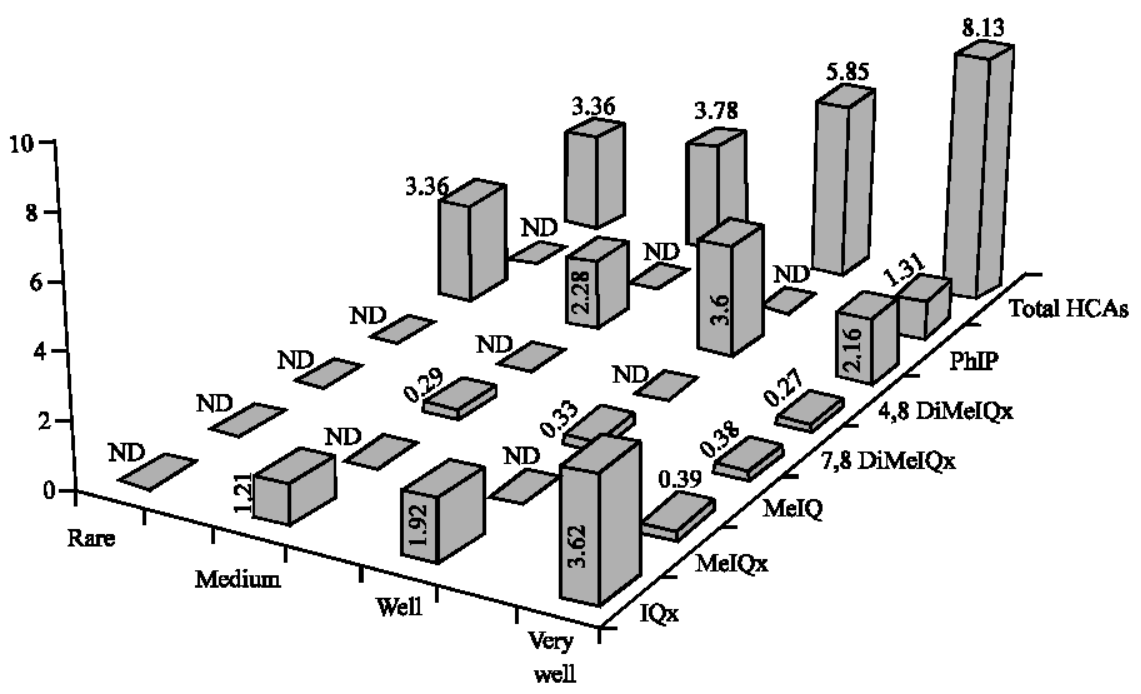

Fig. 1: HCAs in cooked chicken chops $\left(\mathrm{ng} \mathrm{g}^{-1}\right)$

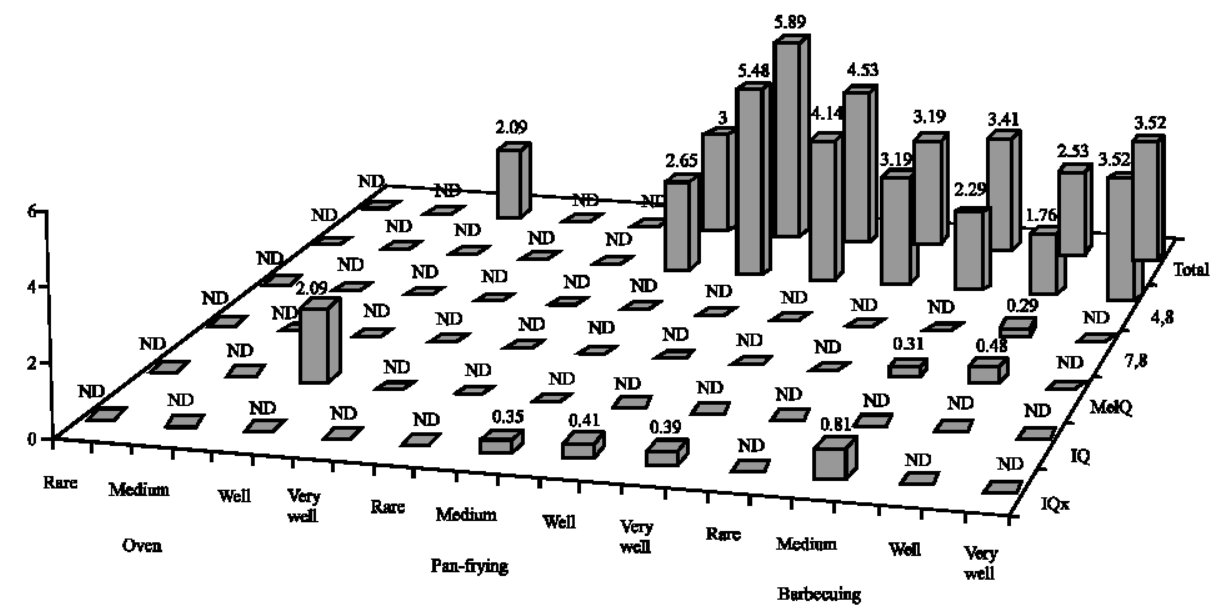

Fig. 2: HCAs in cooked fish fillets $\left(\mathrm{ng} \mathrm{g}^{-1}\right)$

frying. 4,8-DiMeIQx was found in amounts up to around $4 \mathrm{ng} \mathrm{g}^{-1}$ in barbecued chicken for all degrees of doneness. However, increasing the cooking level in barbecued samples increased total HCA content. While the difference of the total HCA content between rare and medium cooking levels was minor, the difference of the total HCA content between well done and rare and between very well done and rare level barbecued chicken samples was 1.7 and 2.4 fold, respectively.

The HCA content of rainbow trout: HCA amount in cooked fish fillets extracted according to the PRS method was given in Fig. 2. HCA contents of fish samples cooked with microwave and hot plate at every degree of doneness were undetectable levels. For oven-cooking of fish,
$2.09 \mathrm{ng} \mathrm{g}^{-1}$ total HCAs amount was only detected in well done cooked samples, all of which was IQ. In the other cooking levels, no HCA could be detected. Although, HCAs could not be detected in rare level pan-fried fish, total HCA amounts for medium, well done and very well done cooking levels reached to $3.0,5.89$ and $4.53 \mathrm{ng} \mathrm{g}^{-1}$, respectively. Barbecuing of fish fillets formed HCAs for all cooking doneness. It was determined that total HCA amount for rare, medium, well done and very well done cooking levels was $3.19,3.41,2.53$ and $3.52 \mathrm{ng} \mathrm{g}^{-1}$, respectively. In addition, important part of total HCAs amount belonged to 4,8-DiMeIQx compounds (Fig. 2). It is also interesting that MeIQx and PhIP compounds, the most abundant HCAs in meat and fish, could not be detected in rainbow trout. This is not the first time that we 
couldn't find this compound not only rainbow trouts but also brown trouts cooked with different techniques (Ozet al., 2007).

\section{DISCUSSION}

We found that the average recoveries for nine HCAs changed between 26 and $75 \%$ for the PRS method. In the studies using the PRS extraction method, Felton et al. (1994) and Knize et al. $(1994,1995)$ found that the average recoveries were $26-80,46-71$ and $30-68 \%$, respectively.

The levels of HCAs found in the present study for chicken samples extracted by the PRS method are in the same range with other studies (Tikkanen et al., 1996; Skog et al., 1997; Solyakov and Skog, 2002; Busquets et al., 2004) (IQx and 7,8-DiMeIQx were also detected in the present study). However, the results are quite different with data from Sinha et al. (1995) who found that total HCAs (4,8-DiMeIQx, MeIQx and PhIP) of pan-fried, oven-broiled and grilled/barbecued skinless, boneless chicken breasts ranged from 14-77, 6-153 and 27-491 ng g ${ }^{-1}$, respectively. In contrast to this study, we found that the total HCA amounts of chicken sample were $<10 \mathrm{ng} \mathrm{g}^{-1}$ for all conditions. The big difference between these results and the results of Sinha et al. (1995) is about PhIP. Although, Sinha et al. (1995) determined $480 \mathrm{ng} \mathrm{g}^{-1} \mathrm{PhIP}$ in very well done grilled/barbecued skinless and boneless chicken breasts, we only detected $1.31 \mathrm{ng} \mathrm{g}^{-1} \mathrm{PhIP}$ in very well done barbecued chicken.

Skog et al. (1997) stated that chicken meat roasted at $150-200^{\circ} \mathrm{C}$ for $30 \mathrm{~min}$ contained little or no IQ, MeIQ, MeIQx and 4,8-DiMeIQx and amount of PhIP of the same samples was below $0.03 \mathrm{ng} \mathrm{g}^{-1}$. While no IQ was detected in chicken grilled at $175-200^{\circ} \mathrm{C}$ for $13 \mathrm{~min}$, below $0.1 \mathrm{ng} \mathrm{g}^{-1}$ MeIQ, $0.3 \mathrm{ng} \mathrm{g}^{-1} \mathrm{MeIQx}, 0.4 \mathrm{ng} \mathrm{g}^{-1}$ 4,8-DiMeIQx and $2.3 \mathrm{ng} \mathrm{g}^{-1} \mathrm{PhIP}$ was found by Busquets et al. (2004). IQ and $\mathrm{MeIQx}$ content of chicken fried $100-200^{\circ} \mathrm{C}$ for $15 \mathrm{~min}$ varied between 0.09 and $0.51 \mathrm{ng} \mathrm{g}^{-1}$ and between 0.08 and $0.91 \mathrm{ng} \mathrm{g}^{-1}$, respectively (Chiu et al., 1998). While the lowest value for MeIQ, 4,8-DiMeIQx and $\mathrm{PhIP}$ compounds was undetectable levels, the highest values for these compounds was $1.21,0.78$ and $2.81 \mathrm{ng} \mathrm{g}^{-1}$, respectively.

It was determined that boiling chicken meat contained no MeIQx, 4,8-DiMeIQx and PhIP and harman and norharman in amounts up to $0.5 \mathrm{ng} \mathrm{g}^{-1}$ (Solyakov and Skog, 2002). Same researchers found that deep-fat frying of chicken breasts produced traces of $\mathrm{MeIQx}, 4,8-$ DiMeIQx and PhIP. It was also determined that pan-frying of chicken breast contained MeIQx in amounts up to $1.8 \mathrm{ng} \mathrm{g}^{-1}, 4,8$-DiMeIQx in amounts up to $0.6 \mathrm{ng} \mathrm{g}^{-1}$ and $\mathrm{PhIP}$ in amounts up to $38.2 \mathrm{ng} \mathrm{g}^{-1}$. For oven-cooking, the results are in agreement with results from Solyakov and Skog (2002), who reported that oven-cooking of chicken yielded in general non-detectable amounts of MeIQx and $\mathrm{PhIP}$; however, the samples were not tested for IQx, IQ, MeIQ and 7,8-DiMeIQx. We could not also detected MeIQx and PhIP in oven-cooked chicken. Tikkanen et al. (1996) found $0.11 \mathrm{ng} \mathrm{g}^{-1} \mathrm{MeIQx}, 0.13 \mathrm{ng} \mathrm{g}^{-1}$ 4,8-DiMeIQx and $4.5 \mathrm{ng} \mathrm{g}^{-1} \mathrm{PhIP}$ in chicken grilled at $220^{\circ} \mathrm{C}$ for $40 \mathrm{~min}$. Murkovic et al. (1997) detected that the concentration of IQ, MeIQ, MeIQx, 4,8-DiMeIQx and PhIP was 1.1, 0.9, 1.4, 0.4 and $3.8 \mathrm{ng} \mathrm{g}^{-1}$ in fried turkey for $20 \mathrm{~min}$.

The present data on the total HCA amount in fish are of the same magnitude as reported earlier for fish samples, although the cooking conditions and fish species are different. Knize et al. (1995) were unable to detect MeIQx, $\mathrm{PhIP}$ and 4,8-DiMeIQx in eighty fast-food fish samples. Zimmerli et al. (2001) were also unable to detect IQ, MeIQ, MeIQx, 4,8-DiMeIQx and PhIP in household and restaurant type steamed salmon and fried fish sticks and oven-roasted fish nuggets. Yamaizumi et al. (1986) determined that $\mathrm{IQ}$ and $\mathrm{MeIQ}$ content of broiled fish ranged from 0.3 and $1.8 \mathrm{ng} \mathrm{g}^{-1}$ and 0.6 and $2.8 \mathrm{ng} \mathrm{g}^{-1}$, respectively. About $0.1 \mathrm{ng} \mathrm{g}^{-1} \mathrm{MeIQx}, 0.03 \mathrm{ng} \mathrm{g}^{-1} 4,8-$ DiMeIQx and $1.37 \mathrm{ng} \mathrm{g}^{-1} \mathrm{PhIP}$ was detected in fried fish by Salmon et al. (2006). The highest value of MeIQx and $\mathrm{PhIP}$ compounds in barbecued fish was detected as 0.03 and $5.5 \mathrm{ng} \mathrm{g}^{-1}$, respectively by Tikkanen et al. (1993).

$\mathrm{Oz}$ et al. (2007) studied effects of different cooking methods (deep-fat frying, pan-frying, grilling and barbecuing) with various times (4-20 $\mathrm{min}$ ) on formation of HCAs in rainbow and brown trouts by the Oasis extraction method and found that the highest amounts of IQ and 4,8-DiMeIQx compounds was found as 0.12 and $0.02 \mathrm{ng} \mathrm{g}^{-1}$, respectively. However, the researches could not detect $\mathrm{MeIQ}, \mathrm{MeIQx}$ and $\mathrm{PhIP}$ in any samples.

Zhang et al. (1988) found $0.16 \mathrm{ng} \mathrm{g}^{-1} \mathrm{IQ}, 0.03 \mathrm{ng} \mathrm{g}^{-1}$ MeIQ, $6.44 \mathrm{ng} \mathrm{g}^{-1} \mathrm{MeIQx}, 0.1 \mathrm{ng} \mathrm{g}^{-1}$ 4,8-DiMeIQx and $69.2 \mathrm{ng} \mathrm{g}^{-1} \mathrm{PhIP}$ in fish fried at $260^{\circ} \mathrm{C}$ for $16 \mathrm{~min}$. It was determined that MeIQx and $\mathrm{PhIP}$ amounts of fish fried at $200^{\circ} \mathrm{C}$ for $6-24 \mathrm{~min}$ varied between 1.4 and $5.0 \mathrm{ng} \mathrm{g}^{-1}$ and between 1.7 and $17.0 \mathrm{ng} \mathrm{g}^{-1}$, respectively (Gross and Gruter, 1992). Although, Pais et al. (1999) could not detect $\mathrm{MeIQx}$ and 4,8-DiMeIQx in fish fried $275^{\circ} \mathrm{C}$ for $30 \mathrm{~min}$, $3.2 \mathrm{ng} \mathrm{g}^{-1} \mathrm{PhIP}$ was detected.

\section{CONCLUSION}

Many previous studies have shown that cooking methods and time are very important for the formation of heterocyclic aromatic amines. The effects of several cooking methods on HCA levels, including cooking 
degrees of doneness, in chicken and fish were investigated by the present study. HCAs are formed generally in cooked meat. No $\mathrm{A} \alpha \mathrm{C}$ and $\mathrm{MeA} \alpha \mathrm{C}$ compounds could be detected in any samples studied.

\section{ACKNOWLEDGEMENTS}

This study has been supported by The Scientific and Technological Research Council of Turkey (TUBITAK)Agriculture, Forestry and Veterinary Research Grant Committee (TOVAG-1050165).

\section{REFERENCES}

Busquets, R., M. Bordas, F. Toribio, L. Puignou and M.T. Galceran, 2004. Occurrence of heterocyclic amines in several home-cooked meat dishes of the Spanish diet. J. Chrom. B, 802: 79-86.

Chiu, C.P., D.Y. Yang and B.H. Chen, 1998. Formation of heterocyclic amines in cooked chicken legs. J. Food Prot., 61: 712-719.

Felton, J.S., M.G. Knize, C. Wood, B.J. Wuebbles and S.K. Healey et al., 1984. Isolation and characterization of new mutagens from fried ground beef. Carcinogenesis, 5: 95-102.

Felton, J.S., E. Fultz, F.A. Dolbeare and M.G. Knize, 1994. Reduction of heterocyclic aromatic amine mutagens/carcinogens in fried beef patties by microwave pretreatment. Food Chem. Toxicol., 32: 897-903.

Felton, J.S., M.A. Malfatti, M.G. Knize, C.P. Salmon, E.C. Hopmans and R.W. Wu, 1997. Health risks of heterocyclic amines. Mutat. Res., 376: 37-41.

Gross, G.A. and A. Gruter, 1992. Quantification of mutagenic/carcinogenic heterocyclic aromatic amines in food products. J. Chromatogr. A, 592: 271-278.

Gökalp, H.Y., M. Kaya, Y. Tülek and Ö. Zorba, 1999. Practical laboratory guide and quality control in meat and meat products. Atatürk Üniversitesi, Ziraat Fakültesi Yayýnlarý, pp: 71-99.

Jägerstad, M., K. Skog, P. Arvidsson and A. Solyakov, 1998. Chemistry, formation and occurence of genetoxic heterocyclic amines identified in model systems and cooked foods. Z. Lebensm. Unters Forsch. A, 207: 419-427.

Knize, M.G., F.A. Dolbeare, K.L. Carroll, D.H. Moore and J.S. Felton, 1994. Effect of cooking time and temperature on the heterocyclic amine content of fried beef patties. Food Chem. Toxicol., 32: 595-603.

Knize, M.G., R. Sinha, N. Rothman, E.D. Brown and C.P. Salmon et al., 1995. Heterocyclic amine content in fast-food meat products. Food Chem. Toxicol., 33: $545-551$.
Murkovic, M., M. Friedrich and W. Pfannhauser, 1997. Heterocyclic aromatic amines in fried poultry meat. Z. Lebensm. Unters Forsch. A, 205: 347-350.

Oz, F. and M. Kaya, 2006. Mutagenic and carcinogenic heterocyclic aromatic amines. FEBS J., 273: $77-367$.

Oz, F., G. Kaban and M. Kaya, 2007. Effects of cooking methods on the formation of heterocyclic aromatic amines of two different species of trout. Food Chem., 104: 67-72.

Pais, P., C.P. Salmon, M.G. Knize and J.S. Felton, 1999. Formation of mutagenic/carcinogenic heterocyclic amines in dry-heated model systems, meats and meat drippings. J. Agric. Food Chem., 47: 1098-1108.

Salmon, C.P., M.G. Knize, J.S. Felton, B. Zhao and A. Seow, 2006. Heterocyclic aromatic amines in domestically prepared chicken and fish from Singapore Chinese households. Food Chem. Toxicol., 44: 484-492.

Sanz Alaejos, M., J.H. Ayala, V. González and A.M. Afonso, 2008. Analytical methods applies to the determination of heterocyclic aromatic amines in foods. J. Chrom. B, 862: 15-42.

Sinha, R., N. Rothman, E.D. Brown, C.P. Salmon and M.G. Knize et al., 1995. High concentrations of the carcinogen2-amino-1-methyl-6-phenylimidazo-[4,5-b] pyridine (PhIP) occur in chicken but are dependent on the cooking method. Cancer Res., 55: 4516-4519.

Skog, K., 2004. Blue cotton, blue rayon and blue chitin in the analysis of heterocyclic aromatic amines-A review. J. Chromatogr. B, 802: 39-44.

Skog, K., K. Augustsson, G. Steineck, M. Stenberg and M. Jägerstad, 1997. Polar and non-polar heterocyclic amines in cooked fish and meat products and their corresponding pan residues. Food Chem. Toxicol., 35: $555-565$.

Solyakov, A. and K. Skog, 2002. Screening for heterocyclic amines in chicken cooked in various ways. Food Chem. Toxicol., 40: 1205-1211.

Sugimura, T.S., 1995. History, Present and Future of Heterocyclic Amines, Cooked Food Mutagens. In: Heterocyclic Amines in Cooked Foods: Possible Human Carcinogens, Adamson, R.H. (Ed.). Princeton Scientific Publishing Co., Princeton, New Jersey, pp: 214-231.

Tikkanen, L.M., T.M. Sauri and K.J. Latva-Kala, 1993. Screening of heat-processed finnish foods for the mutagens 2-amino-3,8-dimethylimidazo [4,5-f]quinoxaline, 2-amino-3,4,8-trimethylimidazo [4,5-f]quinoxaline and 2-amino-1-methyl-6phenylimidazo[4,5-b]pyridine. Food Chem. Toxicol., 31: 717-721. 
Tikkanen, L.M., K.J. Latva-Kala and R.L. Heiniö, 1996. Effect of commercial marinades on the mutagenic activity, sensory quality and amount of heterocyclic amines in chicken grilled under different conditions. Food Chem. Toxicol., 34: 725-730.

Yamaizumi, Z., H. Kasai, S. Nishimura, C.G. Edmons and J.A. Mccloskey, 1986. Stable isotope dilution quantification of mutagens in cooked foods by combined liquid chromatography-thermospray mass spectrometry. Mutat. Res., 173: 1-7.
Zhang, X.M., K. Wakabayashi, Z.C. Liu, T. Sugimura and M. Nagao, 1988. Mutagenic and carcinogenic heterocyclic amines in Chinese cooked foods. Mutat. Res., 201: 181-188.

Zimmerli, B., P. Rhyn, O. Zoller and J. Schlatter, 2001. Occurrence of heterocyclic aromatic amines in the Swiss diet: Analytical method, exposure estimation and risk assessment. Food Additives Contaminants, 18: $533-551$. 